\title{
Quantitative Analysis of the Sources of Construction Waste
}

\author{
Olusanjo O. Fadiya, Panos Georgakis, and Ezekiel Chinyio \\ School of Technology, University of Wolverhampton, Wulfruna Street, WV1 1LY Wolverhampton, UK \\ Correspondence should be addressed to Olusanjo O. Fadiya; sanfad_04@hotmail.com
}

Received 19 May 2014; Accepted 29 September 2014; Published 20 October 2014

Academic Editor: Anaclet Turatsinze

Copyright (C) 2014 Olusanjo O. Fadiya et al. This is an open access article distributed under the Creative Commons Attribution License, which permits unrestricted use, distribution, and reproduction in any medium, provided the original work is properly cited.

\begin{abstract}
The construction industry is traditionally environmentally unfriendly. The environmental impacts of construction waste include soil contamination, water contamination, and deterioration of landscape. Also, construction waste has a negative economic impact by contributing additional cost to construction due to the need to replace wasted materials. However, in order to mitigate waste, construction managers have to explore management options, which include reduction, recycling, and disposal of wastes. Reduction has the highest priority among the waste management options but efficient reduction cannot be achieved without adequate identification of the sources of waste. Therefore, the purpose of this paper is to present a study that was carried out on the contribution rates of nine identified sources of construction waste. Establishing the contribution rates of different waste sources will enhance knowledge-based decision-making in developing appropriate strategy for mitigating construction waste. Quantitative research method, using survey questionnaire, was adopted in this study to assess the frequency and severity of contribution of the sources of waste. As one of the findings of the study, residual waste such as material off-cuts was identified as the highest contributor to construction waste. This study consequently demonstrated that waste has a significant contribution to the cost of construction.
\end{abstract}

\section{Introduction}

Waste may be generated during both the extraction and processing of the raw materials and eventual consumption of final products therein. Rubbles and other waste materials arise from construction activities like demolition, renovation of buildings, and new construction [1]. The construction industry is traditionally environmentally unfriendly $[2,3]$. Construction cultural practice contributes to waste where trade contractors are rewarded for speed rather than their concern for the environmental impact of their work [4]. Furthermore, construction activities consume a large quantity of materials and energy as well as generating unacceptable level of solid waste [3]. The construction industry consumes $25 \%$ of virgin wood and $40 \%$ of raw stone, gravel, and sand globally every year [5]. In the US, the production of building components and construction process itself use $40 \%$ of extracted materials [6]. Construction work leads to land development, land deterioration, resources depletion, waste generation, and various forms of pollution $[7,8]$. The construction industry generates about $35 \%$ of industrial waste in the world $[9,10]$. In the European Union, the construction industry generates a substantial amount of total waste output resulting in between two and five times the quantities of household waste [1]. According to Sir Egan's Rethinking Construction report on the state of UK construction industry, up to $30 \%$ of all construction is rework, labour is used to half of its potential efficiency, and at least $10 \%$ of building materials for every construction project is wasted [11]. However, the huge waste generated by construction activities creates negative environmental, economic, and social impacts. The environmental impacts include soil and water contamination and deterioration of landscape by uncontrolled landfills [12]. Material waste significantly contributes additional cost to construction because new purchases are usually made to replace wasted materials; costs of rework, delays, and disposal cause financial losses to the contractor [13]. Also, construction waste has social impacts such as health and safety of workers and societal image of the construction industry [3].

Construction waste reduction has the highest priority among waste management options which include reduction, recycling, and disposal [14]. Construction management should enhance reduction, reuse, sorting, and recycling of 
waste before disposal [2]. Previous studies on construction waste reduction include operatives' attitudes towards waste reduction [15], direct observation of waste generation [16], and sorting and weighing of waste materials [17]. Recycling plays a crucial role in order to preserve areas for future urban development and to improve, at the same time, local environmental quality [18]. In addition to recycling, inert end-of-life materials can be reused for purposes such as filling materials for land reclamation [19]. Construction waste has a very high recovery potential in which $80 \%$ of total waste can be recycled [17]. Countries such as Denmark, The Netherlands, and Belgium have achieved the aforementioned recycling rate especially given the scarcity of raw materials and disposal sites $[20,21]$. However, the vast majority of construction waste still ends up in landfills [22]. In the UK, a total of 89.6 million tonnes of construction and demolition waste were generated in 2005 of which 28 million tonnes were sent to landfills [23]. About 7 million tonnes of construction and demolition waste was disposed at landfills in Australia in 2006-2007 and 42\% of total was attributed to construction waste [24]. Also in Hong Kong, the disposal of construction waste has become a social and environmental problem because there are acute shortages of landfill spaces [2].

1.1. Sources of Wastes in Construction. Construction material waste arises from design, logistics, and physical construction processes. In the context of this study, construction wastes are some of the materials delivered to site which have been damaged and meant for disposal, reuse, or recycling. According to Ekanayake and Ofori [13], design, operational procurement, and material handling attributes contribute to waste on construction site. Osmani et al. [25] estimated that around $33 \%$ of on-site waste is related to project design. Therefore, reduction of waste should not be the sole responsibility of the construction company, as the client and designer can make environment friendly choices in the program of demands and designs [17]. Studies indicate that waste of materials is usually higher than normal figures assumed by construction companies in their estimates [16]. However, while some level of construction waste is unavoidable, the potential benefit of preventing waste generation on site can be substantial. Furthermore, among the objectives of sustainable development is waste reduction which incorporates both reduction at source and recycling so as to reduce quantities and risks therein [26].

Most previous studies on waste quantification have been focussed on waste segregation for specific materials and the volume of waste generated rather than the impacts of the sources that generated the waste. Bossink and Brouwers [17] conducted a waste segregation research on five construction sites in The Netherlands which demonstrated waste components in percentages of the total amount of waste generated and the research showed that between $1 \%$ and $10 \%$ of each material type delivered to the sites was wasted. Formoso et al. [16] conducted an observation study of the materials delivered to construction sites in Brazil, materials withdrawn
TABLE 1: Sources and causes of construction waste.

\begin{tabular}{|c|c|}
\hline Sources of waste & Causes \\
\hline Procurement & $\begin{array}{l}\text { Ordering error, supplier's error resulting in } \\
\text { excessive materials on site }\end{array}$ \\
\hline Design & Changes to design, documentation error \\
\hline Material handling & $\begin{array}{l}\text { Transportation, off-loading, and } \\
\text { inappropriate storage }\end{array}$ \\
\hline Operations & $\begin{array}{l}\text { Tradesperson's error, for example, installing } \\
\text { wrong materials and having to remove such } \\
\text { materials }\end{array}$ \\
\hline Weather & Humidity, temperature \\
\hline Vandalism & Inadequate security \\
\hline Misplacement & Untraceable materials, abandonment \\
\hline Residual & Cutting materials to sizes \\
\hline Others & Lack of waste management plan \\
\hline
\end{tabular}

from storage, material movements, and construction processes in order to estimate the amount of waste that would be generated. The study showed an average waste volume of $27.6 \%$ spreading across sources such as lack of quality control, handling, off-cuts, and labour error. In Spain, Solis-Guzman et al. [10] developed a waste quantification model that allows total waste volume to be determined and categorised into demolished, wreckage (from construction processes), and packaging waste. The model was tested on a typical new construction project and showed that wreckage forms $82 \%$ of waste that would be generated from the project. However, while the aforementioned previous studies focussed on the volume of waste, this study uniquely measured the severity (in terms of volume) of contribution of the sources and the frequency of their contribution in order to derive the multiplicative impact of the contribution.

Following the identification of the sources of construction waste, this study decided to analyse the identified sources in terms of their waste contributions and impacts. In the United States, Gavilan and Bernold [27] subdivided sources of construction waste into six categories: (1) design; (2) procurement; (3) material handling; (4) operations; (5) residuals; and (6) others. These six were supported and similarly regrouped into categories by Ekanayake and Ofori [13]: design, operational, material handling, and procurement. According to Navon and Berkovich [28], lack of up-to-date information regarding on-site stocks is a typical problem on large construction projects; for lack of information about supply and location of materials on site, the same materials are ordered again resulting in waste. Furthermore, waste can occur at any stage of construction not only because of construction activities but also due to external factors such as theft and vandalism [17]. Hence, the aforementioned sources of waste were combined in this study and categorised as shown in Table 1 . The categorisation shown in Table 1 was adopted for the purpose of conducting the survey in this study.

In order to have adequate record of waste and then develop tools for waste reduction, there is a need to identify the sources of waste and assess their impacts on project 
outcomes [29]. Despite the fact that considerable research efforts have been done for the identification of the sources of construction waste, there is a need for research targeting the analysis of the identified sources in terms of their waste contribution rates and impacts. Hence, the aim of this study is to analyse the rates of contribution of the sources of construction waste which have been identified in previous studies. The analysis of such rates will enhance a more accurate estimation of the cost of waste and the development of appropriate strategy for the mitigation of waste. The accurate estimation of the cost of waste will enhance reasonable comparison with the cost of measures that can be adopted to mitigate waste. In order to achieve the aforementioned aim, a survey was carried out to elicit the perceptions of building contractors of the contributions of different sources of construction waste.

The subsequent contents of this paper are presented as follows. Section 2 describes the research methodology. This is followed by a presentation of data analysis and results in Section 3. Section 4 presents the discussion of results. The paper then concludes with a summary of the contribution of this study on the sources of construction waste in Section 5 .

\section{Research Methodology}

The research methodology adopted in this study was quantitative research method in the form of questionnaire sample survey. Quantitative research is defined as an inquiry into a social or human problem based on testing a hypothesis composed of variables with numbers and analysing with statistical procedure to determine whether the hypothesis holds true [30]. Quantitative research methods are typically sample survey and experiment. Experimental research is based on the researcher manipulating certain controlled conditions in order to establish the relationship between particular variables and explain cause and effect relationships [31]. In questionnaire survey, statistical methods are used to design a representative sample which will derive findings that can generalise the whole population $[32,33]$. The sample survey method of quantitative research conforms with the objective of this study which is to assess knowledge-based opinions of UK construction professionals on the sources contributing to waste on construction sites. The research process was carried out according to the following stages:

(1) research design;

(2) sampling and data collection.

2.1. Research Design. With sources of construction waste as the independent variables, a survey questionnaire was developed to measure the opinions of building contractors on the severity and frequencies of the contribution of these sources using a Likert scale, which is a multi-item measuring scale where response levels are anchored with consecutive integers and symmetrical about a neutral middle [34]. It is an acceptable way of eliciting the strength of opinions using numbers to represent implicit meanings [35-37]. The response levels were presented to respondents on a 5-point scale as follows:
(1) severity of contribution: the scale was 1 (none), 2 (little), 3 (moderate), 4 (great), and 5 (extreme);

(2) frequency of contribution: the scale was 1 (never), 2 (rarely), 3 (sometimes), 4 (frequently), and 5 (always).

The questionnaire was divided into two parts. The first part sought the background of the respondent, size of their company, catchment area of their projects, annual turnover, and headcount. The second part sought to measure the severity and frequency of waste generation sources. Severity rating is a measure of the extent of the impact of these sources in terms of volume of waste that can be generated while frequency rating is a measure of how often the sources do contribute to construction waste. The product of severity and frequency ratings will produce the significance of the contribution of the sources. An example of a question and response to the questionnaire is shown in Table 2.

2.2. Sampling and Data Collection. In a questionnaire survey, statistical methods should be used to design a representative sample which will derive findings that are able to reflect the whole population $[32,33]$. The sample was selected to achieve a representation of building and civil engineering contractors in the UK with the aim of obtaining opinions across the board from contractors that operate regionally and nationally. Contacts were obtained from the KOMPASS online database, which is a "business to business" search engine for building and civil engineering contractors. KOMPASS has a listing of contractors, from which 220 companies were randomly sampled and approached; 55 replies were obtained with 51 (23.1\% of the original sample) fully completed and 4 uncompleted. According to de Vaus [32], it is expected that a small sample size can suffice in a homogeneous population in which most people will answer a question similarly. Furthermore, the more uniform and consistent a population is, the smaller a sample that can be drawn from it for a research purpose is [36]. Therefore, a small sample size of 51 was deemed acceptable in this study because the population of the respondents is expectedly uniform and their responses are expected to be consistent in relation to the issue of construction waste. The population of building and civil engineering contractors from whom responses were obtained are all contractors that operate locally and nationally in the UK and internationally having projects in other countries. Also, the responses are expected to be consistent because the targeted respondents are highly experienced construction professionals. Tables 3 and 4 show the profiles of the respondents and the classification of companies associated with their responses. Table 3 shows that $76 \%$ of respondents have over 20 years of construction experience which means they are professionals with deep knowledge of the sources that contribute to construction waste. In Table $4,68.3 \%$ of the companies are operating at the national and international (UK and abroad) stage which substantiates the respondents' understanding of the levels of construction waste across United Kingdom and other countries. 
TABLE 2: Severity of contribution of the sources of construction waste.

Sources of construction waste

Severity: please rate the following sources of waste according to the degree of their contribution to construction material waste (1 being no contribution and 5 being extreme contribution)

Sources of waste

Contribution rate

None Little Moderate Great Extreme

(a) Procurement such as ordering error and supplier's error due to inaccurate data

$\begin{array}{lllll}1 & 2 & 3 & 4 & 5\end{array}$

(b) Design such as changes to design and contract document errors

(c) Materials handling such as damage during transportation, off-loading, on-site distribution, and inappropriate storage

(d) Operation such as tradesperson's error and equipment malfunction

(e) Damage due to weather such as temperature and humidity

(f) Security such as damage on construction site due to vandalism

(g) Materials misplacement on site

(h) Residual such as off-cuts from cutting materials to length and packaging

(i) Others such as lack of site materials control and waste management plans

\begin{tabular}{lllll}
$\square$ & $\square$ & $\sqrt{ }$ & $\square$ & $\square$ \\
$\square$ & $\square$ & $\square$ & $\sqrt{ }$ & $\square$ \\
$\square$ & $\square$ & $\square$ & $\sqrt{ }$ & $\square$ \\
$\square$ & $\square$ & $\sqrt{ }$ & $\square$ & $\square$ \\
$\square$ & $\square$ & $\square$ & $\sqrt{ }$ & $\square$ \\
$\square$ & $\square$ & $\square$ & $\sqrt{ }$ & $\square$ \\
$\square$ & $\square$ & $\sqrt{ }$ & $\square$ & $\square$ \\
$\square$ & $\square$ & $\square$ & $\sqrt{ }$ & $\square$ \\
$\square$ & $\square$ & $\sqrt{ }$ & $\square$ & $\square$ \\
\hline
\end{tabular}

TABLE 3: Roles and years of experience of respondents.

\begin{tabular}{lccccc}
\hline Roles & Number of responses & Percentage of responses & Years of experience & Number of responses & Percentage of responses \\
\hline $\begin{array}{l}\text { Director/senior } \\
\text { management }\end{array}$ & 24 & 47.06 & $0-10$ & 3 & 9.88 \\
Managers & 14 & 27.45 & $11-20$ & 14 & 17.65 \\
Others & 13 & 25.49 & $>25$ & 25 & 27.45 \\
Totals & $\mathbf{5 1}$ & $\mathbf{1 0 0 \%}$ & Totals & $\mathbf{5 1}$ & 49.02 \\
\end{tabular}

TABLE 4: Classification of respondents' companies.

\begin{tabular}{lcc}
\hline & $\begin{array}{c}\text { Number of } \\
\text { responses }\end{array}$ & $\begin{array}{c}\text { Percentage of } \\
\text { responses }\end{array}$ \\
\hline Work catchment areas & 16 & 31.37 \\
$\quad$ Regional contractors & 20 & 39.22 \\
$\quad$ National contractors & 15 & 29.41 \\
$\quad$ International contractors & & \\
Size by annual turnover £M sterling & 7 & 13.73 \\
$>1.7$ M but $\leq 8.5 \mathrm{M}$ & 21 & 41.17 \\
$>8.5$ M but $\leq 43 \mathrm{M}$ & 23 & 45.10 \\
$>43 \mathrm{M}$ & & \\
Size by headcount & 2 & 3.92 \\
Up to 10 & 11 & 21.57 \\
10-50 & 15 & 29.41 \\
$50-250$ & 23 & 45.10 \\
Over 250 & &
\end{tabular}

\section{Data Analysis and Results}

The questionnaire responses were analysed using ordinal logistic regression to derive the probabilities of rating categories $(1,2,3,4$, and 5$)$ for the severity and frequency of the contribution of the sources of construction waste using SPSS software. The probability of a category (e.g., 2) is the number of respondents that chose the category divided by the total number of respondents in the sample. The output of the ordinal logistic regression analysis of the severity of design in contributing to construction waste is highlighted in Table 5. Consequent upon the derivation of probabilities of individual categories of severity and frequency of contribution of each source of waste, these probabilities were aggregated to derive severity and frequency indices. The probability of category 1 $\left(X_{1}\right.$ or $\left.Y_{1}\right)$ was excluded in the calculations of severity and frequency indices because it represents "None" or "Never" on the Likert scale which means category 1 has a resultant zero weight in the measure of contribution of the sources to construction waste.

As demonstrated in Fadiya et al. [38], the following formulae were used to derive severity and frequency indices:

$$
\begin{gathered}
S_{j}=\sum_{i=2}^{5} w_{i} X_{i} ; \quad w_{i}=\frac{i}{5} ; X_{i}=\frac{m_{i}}{N} \\
F_{j}=\sum_{i=2}^{5} w_{i} Y_{i} ; \quad w_{i}=\frac{i}{5} ; Y_{i}=\frac{n_{i}}{N}
\end{gathered}
$$

where $i$ is the rating category; $m_{i}$ is number of respondents that chose $i$ for the severity; $n_{i}$ is the number of respondents that chose $i$ for the frequency; $N$ is the total number of responses; $w_{i}$ is the weight of category $i$; and $j$ is the series of sources of construction waste. 
TABLE 5: Ordinal logistic regression analysis result for severity of the sources of waste.

\begin{tabular}{lccccc}
\hline \multirow{2}{*}{ Sources of waste } & \multicolumn{4}{c}{ Probabilities for response categories on severity of sources of waste $\left(m_{i} / N\right)$} \\
& Category: $1.00\left(X_{1}\right)$ & Category: $2.00\left(X_{2}\right)$ & Category: 3.00 $\left(X_{3}\right)$ & Category: $4.00\left(X_{4}\right)$ & Category: $5.00\left(X_{5}\right)$ \\
\hline Data error & 0.000 & 0.275 & 0.451 & 0.196 & 0.078 \\
Design & 0.000 & 0.157 & 0.529 & 0.255 & 0.059 \\
Handling & 0.000 & 0.176 & 0.510 & 0.275 & 0.039 \\
Operations & 0.000 & 0.176 & 0.706 & 0.118 & 0.216 \\
Weather & 0.000 & 0.294 & 0.490 & 0.176 & 0.000 \\
Vandalism & 0.000 & 0.196 & 0.627 & 0.235 & 0.000 \\
Misplacement & 0.020 & 0.235 & 0.510 & 0.294 & 0.000 \\
Residual & 0.000 & 0.216 & 0.392 & 0.255 & 0.098 \\
Others & 0.000 & 0.235 & 0.471 & & 0.039 \\
\hline
\end{tabular}

The computed severity and frequency indices of the sources of construction waste are shown in Tables 6 and 7, respectively. As a guide, the severity index of design change using the probabilities shown in Table 5 was derived as follows:

$$
\begin{aligned}
& S_{\text {Design }} \\
& =\frac{(2 \times 0.157+3 \times 0.529+4 \times 0.255+5 \times 0.059)}{5} \\
& =0.643 .
\end{aligned}
$$

Adopting a similar method applied by Assaf and Al-Hejji [35], the severity and frequency indices in Tables 6 and 7 were combined using (3) to derive the contribution indices. According to Fadiya et al. [39], the contribution index is a measure of significance of each source while severity index is a measure of the extent of contribution and frequency index is a measure of how often a source contributes. Furthermore, the contribution indices were converted to rates according to (4) in order to generate percentages of contribution of the sources to construction waste. Hence, the severity indices, frequency indices, contribution indices, and rates of contribution of the sources of construction waste are shown in Table 8. Consider

$$
\begin{aligned}
& \text { Contribution index }\left(C_{j}\right)=S_{j} * F_{j}, \\
& \text { Rates }=\frac{C_{j}}{\sum_{i=1}^{9} C_{j}} * 100 \% .
\end{aligned}
$$

3.1. Test of the Significance of the Statistics. In addition to the typical values derived in Section 2.2, the significance of the statistics of the severity and frequency of the variables was examined using the Chi-Square test. Significance level testing is estimating how likely the sample pattern will hold in the population. The test starts by assuming a particular pattern in the population-the null hypothesis. A significance level is typically set at 0.05 , but sometimes it can be adjusted to as little as 0.01 or as much as 0.1 . The decision to adjust it is based on the tolerance for the two types of error, that is, either rejecting the null hypothesis that is true or not rejecting the hypothesis that is false [40]. Rejecting the null hypothesis when it is true is called Type I error while accepting the hypothesis that is false is a Type II error. Adopting 0.05 significance level means there is higher probability of rejecting a true hypothesis while adopting 0.01 significance level means lower probability of rejecting a true hypothesis but a higher probability of accepting a false hypothesis $[32,41]$. It is difficult to assess the probability of committing either of these two types of error but 0.05 is a compromise that attempts to minimise the probability of committing either of the two types of error [41].

The Chi-Square test was employed in order to analyse the percentages in the population for all the categories $(1,2,3,4$, and 5). The purpose of the test was to assess the variability of ratings that were assigned to the severity and frequency of the sources of construction waste by the respondents. The null hypothesis was as follows:

$\mathrm{H}_{0}$ : the percentages of all categories for each source of waste are equal in the underlying population.

The Chi-Square test statistics for both severity and frequency of the sources of construction waste are shown in Table 9. The results indicated differences between the expected percentages of categories (null hypothesis/equal percentages) and the observed percentages of categories (unequal percentages). Table 9 shows that these differences in the percentages are significant and are not due to chance $(P<0.05)$. This provides statistical evidence to reject the null hypothesis and uphold the results of the statistical analysis.

\section{Discussion of Results}

As described Section 3, the contribution index is a measure of the significance of contribution of each source of construction waste. The minimum contribution index in the scale is $0.16\left(S_{i}=2 / 5 \times F_{i}=2 / 5\right)$ while the maximum contribution is $1\left(S_{i}=5 / 5 \times F_{i}=5 / 5\right)$. The results in Figure 1 show that residual has the highest contribution (Rate $=13.2 \%$ ). Residual source of waste includes off-cuts from materials being cut to length and packaging. In the second place in terms of contribution is design ( Rate $=13.1 \%$ ) while the source of waste with the minimum contribution is vandalism (Rate $=9.5 \%$ ).

The results of this study are corroborated by existing findings. According to Osmani et al. [25], project design 


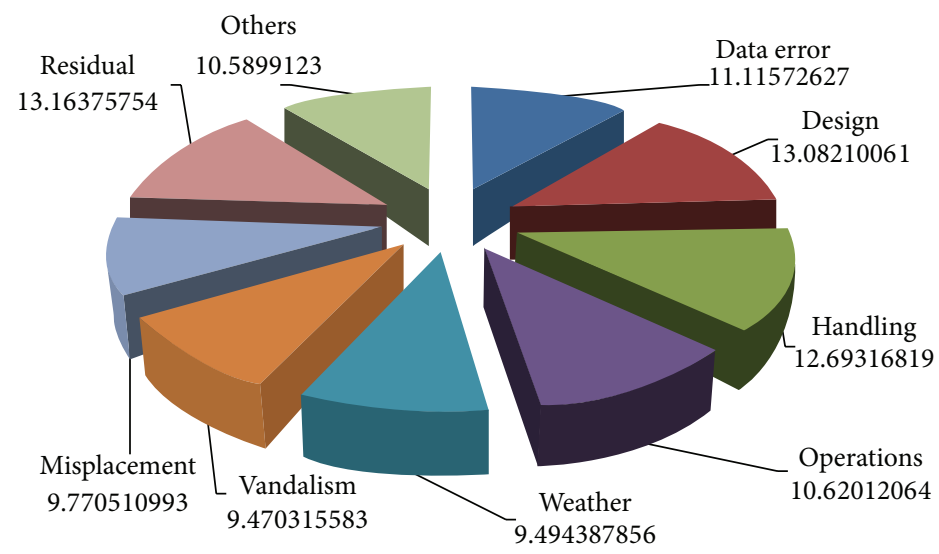

FIGURE 1: Contribution rates of the sources of construction waste.

TABLE 6: Severity indices of the sources of construction waste.

\begin{tabular}{lccccc}
\hline \multirow{2}{*}{ Sources } & \multicolumn{6}{c}{ Probabilities for response categories } & \multirow{2}{*}{$S_{i}$} \\
& $X_{2}$ & $X_{3}$ & $X_{4}$ & $X_{5}$ & \\
\hline Data error & 0.2745 & 0.4510 & 0.1961 & 0.0784 & $\mathbf{0 . 6 1 5 7}$ \\
Design & 0.1569 & 0.5294 & 0.2549 & 0.0588 & $\mathbf{0 . 6 4 3 1}$ \\
Handling & 0.1765 & 0.5098 & 0.2745 & 0.0392 & $\mathbf{0 . 6 3 5 3}$ \\
Operations & 0.1765 & 0.7059 & 0.1176 & 0.0000 & $\mathbf{0 . 5 8 8 2}$ \\
Weather & 0.2941 & 0.4902 & 0.2157 & 0.0000 & $\mathbf{0 . 5 8 4 3}$ \\
Vandalism & 0.1961 & 0.6275 & 0.1765 & 0.0000 & $\mathbf{0 . 5 9 6 1}$ \\
Misplacement & 0.2353 & 0.5098 & 0.2353 & 0.0000 & $\mathbf{0 . 5 8 8 2}$ \\
Residual & 0.2157 & 0.3922 & 0.2941 & 0.0980 & $\mathbf{0 . 6 5 4 9}$ \\
Others & 0.2353 & 0.4706 & 0.2549 & 0.0392 & $\mathbf{0 . 6 1 9 6}$ \\
\hline
\end{tabular}

contributes about $33 \%$ of construction waste. Residual wastes could be minimised if design dimensions adapt to standard dimensions of materials. These two major contributors as established in this study account for $26.3 \%$ of construction waste and are related to project design. Furthermore, the results of Chi-Square test demonstrate the significance of the findings of this study. The $P$ values of the severity and frequency of the sources of waste were below 0.05 ; that is, the null hypothesis should be rejected and the results of this study can be accepted as statistically valid.

4.1. Reliability of Results. The reliability of the results of this study is justified by the results of the Chi-Square test. According to DeCoster and Claypool [42], the higher the reliability of the scale of the questionnaire survey is, the easier it is to obtain significant findings. Hence, the rejection of the null hypothesis in the inferential test showed the significance of the findings of this study and demonstrated the reliability of the sample. Furthermore, the agreement of the findings of this study with the findings of a former study demonstrates criterion validity, which, according to Black [43] and de Vaus [32], is how related a new measure of a concept is to the existing measures of the concept. To further demonstrate the validity of the results of this study and the reliability of the internal consistency of the
TABLE 7: Frequency indices of the sources of construction waste.

\begin{tabular}{lccccc}
\hline \multirow{2}{*}{ Sources } & \multicolumn{6}{c}{ Probabilities for response categories } & \multirow{2}{*}{$F_{i}$} \\
& $Y_{2}$ & $Y_{3}$ & $Y_{4}$ & $Y_{5}$ & \\
\hline Data error & 0.1765 & 0.7059 & 0.1176 & 0.0000 & $\mathbf{0 . 5 8 8 2}$ \\
Design & 0.1373 & 0.4118 & 0.4510 & 0.0000 & $\mathbf{0 . 6 6 2 7}$ \\
Handling & 0.1176 & 0.5098 & 0.3725 & 0.0000 & $\mathbf{0 . 6 5 1 0}$ \\
Operations & 0.1961 & 0.6667 & 0.1373 & 0.0000 & $\mathbf{0 . 5 8 8 2}$ \\
Weather & 0.3529 & 0.6471 & 0.0000 & 0.0000 & $\mathbf{0 . 5 2 9 4}$ \\
Vandalism & 0.3725 & 0.5882 & 0.0196 & 0.0000 & $\mathbf{0 . 5 1 7 6}$ \\
Misplacement & 0.3529 & 0.5882 & 0.0588 & 0.0000 & $\mathbf{0 . 5 4 1 2}$ \\
Residual & 0.1765 & 0.4510 & 0.2941 & 0.0784 & $\mathbf{0 . 6 5 4 9}$ \\
Others & 0.2157 & 0.6275 & 0.1176 & 0.0000 & $\mathbf{0 . 5 5 6 9}$ \\
\hline
\end{tabular}

TABLE 8: Contribution indices of the sources of construction waste.

\begin{tabular}{lccccc}
\hline Sources & $S_{i}$ & $F_{i}$ & $C_{i}$ & Rates (\%) & Ranks \\
\hline Data error & 0.6157 & 0.5882 & 0.3622 & 11.12 & 4 \\
Design & 0.6431 & 0.6627 & 0.4262 & 13.08 & 2 \\
Handling & 0.6353 & 0.6510 & 0.4136 & 12.69 & 3 \\
Operations & 0.5882 & 0.5882 & 0.3460 & 10.62 & 5 \\
Weather & 0.5843 & 0.5294 & 0.3093 & 9.494 & 8 \\
Vandalism & 0.5961 & 0.5176 & 0.3086 & 9.47 & 9 \\
Misplacement & 0.5882 & 0.5412 & 0.3183 & 9.771 & 7 \\
Residual & 0.6549 & 0.6549 & 0.4289 & 13.16 & 1 \\
Others & 0.6196 & 0.5569 & 0.3450 & 10.59 & 6 \\
\hline
\end{tabular}

multi-item scales, Cronbach's alpha estimates of the data on the severity and frequency of the sources of construction waste were derived as shown in Table 10. Cronbach's alpha is regarded as the most widely used objective measure of reliability of internal consistency (interrelatedness) of multiitems $[42,44]$. The reliability coefficient ranges from 0 to 1 ; the closer the coefficient to 1.0 , the greater the internal consistency. While there is no hard-and-fast rule on the lower and upper limits of Cronbach's coefficient, acceptable values range from 0.7 to 0.95 [45-47]. Table 10 shows that the alpha value for the severity of the sources of waste is 0.797 which falls within the generally acceptable range; the alpha value for 
TABLE 9: Chi-Square test statistics for sources of construction waste.

\begin{tabular}{lcccc}
\hline \multirow{2}{*}{ Sources } & \multicolumn{2}{c}{ Severity } & \multicolumn{2}{c}{ Frequency } \\
& Chi-Square & $\begin{array}{c}\text { Asymp. } \\
\text { Sig. }(P)\end{array}$ & Chi-Square & $\begin{array}{c}\text { Asymp. } \\
\text { Sig. }(P)\end{array}$ \\
\hline Data error & 14.961 & 0.002 & 32.118 & 0.000 \\
Design & 25.157 & 0.000 & 8.941 & 0.011 \\
Handling & 24.059 & 0.000 & 12.118 & 0.002 \\
Operations & 32.118 & 0.000 & 25.765 & 0.000 \\
Weather & 6.118 & 0.047 & 4.412 & 0.036 \\
Vandalism & 19.882 & 0.000 & 48.059 & 0.000 \\
Material & 24.686 & 0.000 & 21.529 & 0.000 \\
misplacement & 9.471 & 0.024 & 15.745 & 0.001 \\
Residual & 19.039 & 0.000 & 41.941 & 0.000 \\
Others & & & &
\end{tabular}

TABLE 10: Reliability statistics for the multi-item scales of the sources of construction waste.

\begin{tabular}{lcc}
\hline & $\begin{array}{c}\text { Cronbach's alpha if } \\
\text { item deleted (severity) }\end{array}$ & $\begin{array}{c}\text { Cronbach's alpha if } \\
\text { item deleted } \\
\text { (frequency) }\end{array}$ \\
\hline Data error & 0.772 & 0.612 \\
Design & 0.774 & 0.623 \\
Handling & 0.757 & 0.593 \\
Operation & 0.777 & 0.621 \\
Weather & 0.765 & 0.601 \\
Vandalism & 0.786 & 0.622 \\
Material & 0.769 & 0.611 \\
misplacement & 0.818 & 0.626 \\
Residual & 0.772 & 0.577 \\
Others & \multicolumn{2}{c}{ Cronbach's alpha } \\
\hline \multicolumn{2}{c}{0.797} \\
Reliability coefficient & \multicolumn{2}{c}{0.638} \\
for severity & Reliability coefficient & \multicolumn{2}{c}{} \\
for frequency &
\end{tabular}

the frequency, 0.638 , falls outside the range but very close to the lower limit. However, a low value of alpha could be due to a low number of items rather than poor interrelatedness of the items $[44,45]$.

4.2. Estimating the Cost of Construction Waste. This section is presented to demonstrate the application of the contribution rates derived in this study in estimating the cost of material wastes to construction projects. Although some residual level of construction waste is unavoidable, the correlation between waste and cost minimisation is substantial and provides an incentive for participants in construction projects to pursue them [17]. The total cost of waste is the sum of materials cost therein and disposal cost [48]. Hence, (6), (7), and (8) were formulated by authors in order to quantify the total cost of construction waste. Consider

$$
\begin{aligned}
& \text { Cost of Waste } \\
& \text { = Cost of Waste Material + Cost of Disposal }
\end{aligned}
$$

Cost of Waste Material

$$
=\frac{\text { Quantity of Waste }}{\text { Quantity of Materials }} \times \frac{\text { Cost of Material }}{1}
$$

Cost of Waste Disposal

$$
=\frac{\text { Disposal Cost }}{\text { skip }} \times \frac{\text { number of skips }}{1} .
$$

The average volume of a typical skip that collects waste is $6.125 \mathrm{~m}^{3}$ with an average $50 \%$ void [48]. Hence, the volume of skipped waste is twice the actual volume of waste:

$$
\begin{aligned}
\text { Number of Skip } & =\frac{\text { Volume of skipped waste }}{6.125} \\
& =\frac{2 \times \text { Volume of Waste }}{6.125} .
\end{aligned}
$$

For the purpose of demonstration in this paper, the variables of (6), (7), and (8) were derived as follows.

(i) The quantity of waste (volume) can be calculated from gross floor area of a building project using SMARTWaste planning tool developed by Building Research Establishment [49]. This tool was used to derive the volume of waste expected from the construction of an 8-storey commercial office building project with a gross floor area of 54000SF and the volume obtained was $817.94 \mathrm{~m}^{3}$.

(ii) The total quantity of materials was $46954.62 \mathrm{~m}^{3}$ and the total cost of materials for the project was $£ 967,453.00$.

(iii) The cost of waste disposal was estimated to be $£ 1037.17$ per skip [50].

(iv) Number of skips (see (8)) $\Rightarrow$

$$
\text { Number of skips }=\frac{2 \times 817.94}{6.125}=267 \text {. }
$$

(v) Cost of waste disposal (see (7)) $\Rightarrow$

Cost of waste disposal $=1037.17 \times 267=276924.39$. $(10)$

(vi) Cost of waste material (see (6)) $\Rightarrow$

Cost of material waste $=\frac{817.94 \times 967453}{46954.62}=16852.84$.

(vii) Total cost of waste (see (5)) $\Rightarrow$

Cost of waste $=276924.39+16852.84=293777.23$. 
Costs of construction waste with respect to sources $(\mathfrak{E})$

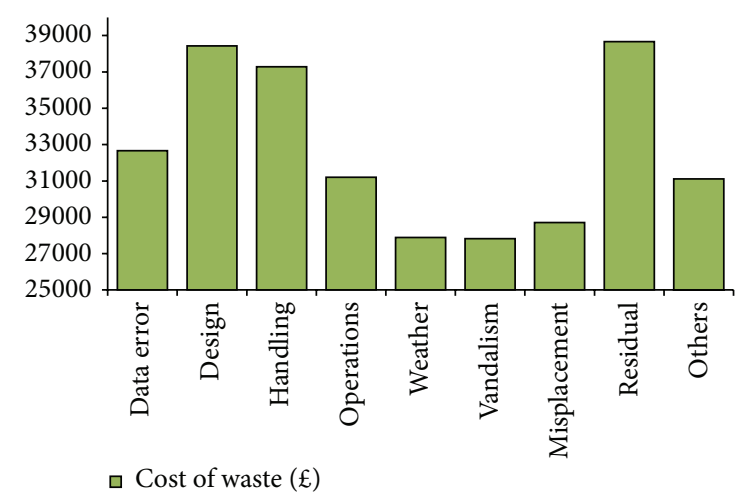

Figure 2: Typical cost stream of the sources of construction waste.

According to Ekanayake and Ofori [13], material waste significantly contributes to the cost of construction. This assertion is corroborated by this example which shows that the total cost of waste ( $£ 293,777)$ is expected to be $30 \%$ of the cost of materials (£967,453) of the project used in this study. The total cost of waste can be distributed across the sources of waste using the rates of contribution derived in Section 3 as shown in Figure 2.

\section{Conclusion}

This study has developed an analytical method of estimating the cost of construction waste. Reliable estimation of the cost of construction waste prior to the commencement of construction activities will help decision makers understand better the cost implication of waste generation and enhance their decision-making in developing the appropriate strategy that can mitigate waste. For example, knowing the extent of contribution and the cost implication of misplacement can help in decision-making on the adoption of information and communication technology- (ICT-) based tracking systems such as radio frequency identification devices (RFID) which can mitigate misplacement and abandonment of materials on large construction sites. Also, consequent upon the findings of this study, waste can be minimised through, for example, design by factoring-in standard dimensions of materials, labour by careful handling of materials during construction, appropriate storage to avoid damage, and so forth.

Furthermore, the findings of this study show that waste is a major contributor to the cost of construction. The total cost of waste is expected to be $30 \%$ of the cost of materials. Also, the rates of contribution and corresponding ranking of the sources of waste will enhance prioritisation of the sources that could be mitigated in the face of financial challenges of mitigation strategies. The 1st, $2 \mathrm{nd}$, and 3rd contributors of construction waste are residual (off-cuts of materials to design dimensions), design change, and material handling, respectively. In the future, key project stakeholders can assess the likely volume and cost of waste using the method developed in this study.

\section{Conflict of Interests}

The authors declare that there is no conflict of interests regarding the publication of this paper.

\section{References}

[1] P. Nowak, M. Steiner, and U. Wiegel, "Waste management challenges for the construction industry," Construction Information Quarterly, vol. 11, no. 1, p. 8, 2009.

[2] A. T. W. Yu, C. S. Poon, A. Wong, R. Yip, and L. Jaillon, "Impact of construction waste disposal charging scheme on work practices at construction site in Hong Kong," Waste Management, vol. 33, no. 1, pp. 138-146, 2013.

[3] H. Yuan, A. R. Chini, Y. Lu, and L. Shen, "A dynamic model for assessing the effects of management strategies on the reduction of construction and demolition waste," Waste Management, vol. 32, no. 3, pp. 521-531, 2012.

[4] G. Sullivan, S. Barthorpe, and S. Robbins, Managing Construction Logistics, John Wiley \& Sons, Blackwell, London, UK, 2010.

[5] U. Kulatunga, D. Amaratunga, R. Haigh, and R. Rameezdeen, "Attitudes and perceptions of construction workforce on construction waste in Sri Lanka," Management of Environmental Quality, vol. 17, no. 1, pp. 57-72, 2006.

[6] C. Kibert and R. Ries, "Green building education and research at the University of Florida," in Proceedings of the 45th ASC International Annual Conference, T. Sulbaran, Ed., Gainesville, Fla, USA, 2009.

[7] G. Ofori, C. Briffett, G. Gang, and M. Ranasinghe, "Impact of ISO 14000 on construction enterprises in Singapore," Construction Management and Economics, vol. 18, no. 8, pp. 935-947, 2000.

[8] W. Y. M. Tam, C. M. Tam, W. W. J. Chan, and C. Y. W. Ng, "Cutting construction by prefabrication," International Journal of Construction Management, vol. 6, no. 1, pp. 15-25, 2006.

[9] C. F. Hendriks and H. S. Pietersen, Sustainable Raw Materials: Construction and Demolition Waste, RILEM Publication, Cachan Cedex, France, 2000.

[10] J. Solis-Guzman, M. Marrero, M. V. Montes-Delgado, and A. Ramírez-de-Arellano, "A Spanish model for quantification and management of construction waste," Waste Management, vol. 29, no. 9, pp. 2542-2548, 2009.

[11] J. Egan, Rethinking Construction: The Report of the Construction Task Force to the Deputy Prime Minister, John Prescott, on the Scope for Improving the Quality and Efficiency of UK Construction, Department for Trade and Industry, London, UK, 1998.

[12] C. Leiva, L. F. Vilches, J. Vale, and C. Fernández-Pereira, "Influence of the type of ash on the fire resistance characteristics of ash-enriched mortars," Fuel, vol. 84, no. 11, pp. 1433-1439, 2005.

[13] L. L. Ekanayake and G. Ofori, "Construction material waste source evaluation," in Proceedings of the Strategies for a Sustainable Built Environment, Pretoria, South Africa, August 2000.

[14] C.-L. Peng, D. E. Scorpio, and C. J. Kibert, "Strategies for successful construction and demolition waste recycling operations," Construction Management and Economics, vol. 15, no. 1, pp. 49-58, 1997.

[15] M. M. M. Teo and M. Loosemore, "A theory of waste behaviour in the construction industry," Construction Management and Economics, vol. 19, no. 7, pp. 741-751, 2001. 
[16] C. T. Formoso, L. Soibelman, C. de Cesare, and E. L. Isatto, "Material waste in building industry: main causes and prevention," Journal of Construction Engineering and Management, vol. 128, no. 4, pp. 316-325, 2002.

[17] B. A. G. Bossink and H. J. H. Brouwers, "Construction waste: quantification and source evaluation," Journal of Construction Engineering and Management, vol. 122, no. 1, pp. 55-60, 1996.

[18] N. Kartam, N. Al-Mutairi, I. Al-Ghusain, and J. Al-Humoud, "Environmental management of construction and demolition waste in Kuwait," Waste Management, vol. 24, no. 10, pp. 10491059, 2004.

[19] C. S. Poon, A. T. W. Yu, and L. H. Ng, "On-site sorting of construction and demolition waste in Hong Kong," Resources, Conservation and Recycling, vol. 32, no. 2, pp. 157-172, 2001.

[20] M. Erlandsson and P. Levin, "Environmental assessment of rebuilding and possible performance improvements effect on a national scale," Building and Environment, vol. 40, no. 11, pp. 1459-1471, 2005.

[21] E. K. Lauritzen, "Emergency construction waste management," Safety Science, vol. 30, no. 1-2, pp. 45-53, 1998.

[22] G. Banias, C. Achillas, C. Vlachokostas, N. Moussiopoulos, and I. Papaioannou, "A web-based decision support system for the optimal management of construction and demolition waste," Waste Management, vol. 31, no. 12, pp. 2497-2502, 2011.

[23] DEFRA, Department for Environment, and Food and Rural Affairs; UK, "Construction and demolition waste management: 1999-2005," 2013, http://webarchive.nationalarchives.gov.uk/ 20130123162956/http:/www.defra.gov.uk/evidence/statistics/ environment/waste/kf/wrkf09.htm.

[24] EPHC, Environmental Protection \& Heritage Council National Waste Overview-Characterization of Building-Related Construction and Demolition Debris in the United States, US Environmental Protection Agency, 2013, http://www.epa.gov/wastes/ hazard/generation/sqg/cd-rpt.pdf.

[25] M. Osmani, J. Glass, and A. D. F. Price, "Architects' perspectives on construction waste reduction by design," Waste Management, vol. 28, no. 7, pp. 1147-1158, 2008.

[26] Y. Yang and L. Shi, "Integrating environmental impact minimization into conceptual chemical process design-a process systems engineering review," Computers \& Chemical Engineering, vol. 24, no. 2-7, pp. 1409-1419, 2000.

[27] R. M. Gavilan and L. E. Bernold, "Source evaluation of solid waste in building construction," Journal of Construction Engineering and Management, vol. 120, no. 3, pp. 536-552, 1994.

[28] R. Navon and O. Berkovich, "An automated model for materials management and control," Construction Management and Economics, vol. 24, no. 6, pp. 635-646, 2006.

[29] J. C. T. Kwan, Tools for Measuring and Forecasting Waste Generated on Site: Scoping Study, Construction Industry Research and Information Association, London, UK, 2001.

[30] J. W. Creswell, Research Design: Qualitative, Quantitative and Mixed Method Approaches, Sage, Thousand Oaks, Calif, USA, 2003.

[31] M. Henn, M. Weinstein, and N. Foard, A Short Introduction of Social Research, Sage Publications, London, UK, 2006.

[32] D. de Vaus, Surveys in Social Research, Routledge, London, UK, 5th edition, 2002.

[33] B. Somekh and C. Lewin, Research Methods in the Social Sciences, Sage, London, UK, 2005.

[34] J. S. Uebersax, "Likert scales: dispelling the confusion," Statistical Methods for Rater Agreement, February 2013, http://www.john-uebersax.com/stat/likert.htm.
[35] S. A. Assaf and S. Al-Hejji, "Causes of delay in large construction projects," International Journal of Project Management, vol. 24, no. 4, pp. 349-357, 2006.

[36] R. Carmichael, D. J. Edwards, and G. D. Holt, "Plant managers' perceptions of plant security systems," Engineering, Construction and Architectural Management, vol. 14, no. 1, pp. 65-78, 2007.

[37] P. Jennings and G. D. Holt, "Prequalification and multi-criteria selection: a measure of contractors' opinions," Construction Management and Economics, vol. 16, no. 6, pp. 651-660, 1998.

[38] O. O. Fadiya, P. Georgakis, E. Chinyio, and P. Akadiri, "Analysing the perceptions of UK building contractors on the contributors to the cost of construction plant theft," Journal of Financial Management of Property and Construction, vol. 18, no. 2, 2013.

[39] O. Fadiya, P. Georgakis, E. Chinyio, and C. Nwagboso, "Perceptions of building contractors concerning plant theft," International Journal of Architecture, Engineering and Construction, vol. 1, no. 1, pp. 47-54, 2012.

[40] J. Mirabella, "Hypothesis testing with SPSS: a non-statistician guide \& tutorial," 2006, http://www.drjimmirabella.com/ ebook/excerpt\%20from\%20Hypothesis\%20Testing\%20with\% 20SPSS\%20ebook\%20(Jim\%20Mirabella).pdf.

[41] A. W. Kerr, H. K. Hall, and S. A. Kozub, Doing Statistics with SPSS, Sage Publications, London, UK, 2002.

[42] J. DeCoster and H. Claypool, Data analysis in SPSS, 2004, http://www.stat-help.com/spss.pdf.

[43] T. R. Black, Evaluating Social Science Research: An Introduction, Sage Publications, London, UK, 1994.

[44] M. Tavakol and R. Dennick, "Making sense of Cronbach's alpha," International Journal of Medical Education, vol. 2, pp. 53$55,2011$.

[45] J. A. Gliem and R. R. Gliem, "Calculating, interpreting and reporting Cronbach's alpha reliability coefficient for Likerttype scales," in Proceedings of the Midwest Research to Practice Conference in Adult, Continuing and Community Education, pp. 82-88, Ohio State University, Columbus, Ohio, USA, 2003.

[46] J. M. Bland and D. G. Altman, "Statistics notes: cronbach's alpha," British Medical Journal, vol. 314, article 275, 1997.

[47] R. DeVellis, Scale Development: Theory and Applications, Sage, Thousand Oaks, Calif, USA, 2003.

[48] G. Hobbs, "Developing a strategic approach to construction waste," 2011, http://www.bre.co.uk/filelibrary/pdf/rpts/waste/ ConstructionWasteReport240906.pdf.

[49] Building Research Establishment, "BRE waste benchmark data," 2010, http://www.smartwaste.co.uk/filelibrary/benchmarks\% 20data/Waste_Benchmarks_for_new_build_projects_by_project_type_28_February_2011.pdf.

[50] The Highland Council, "Charges for the collection and disposal of commercial waste and the hire of waste skips-2011/12," 2010, http://www.highland.gov.uk/download/meetings/id/22562/ item10tec9810pdf. 

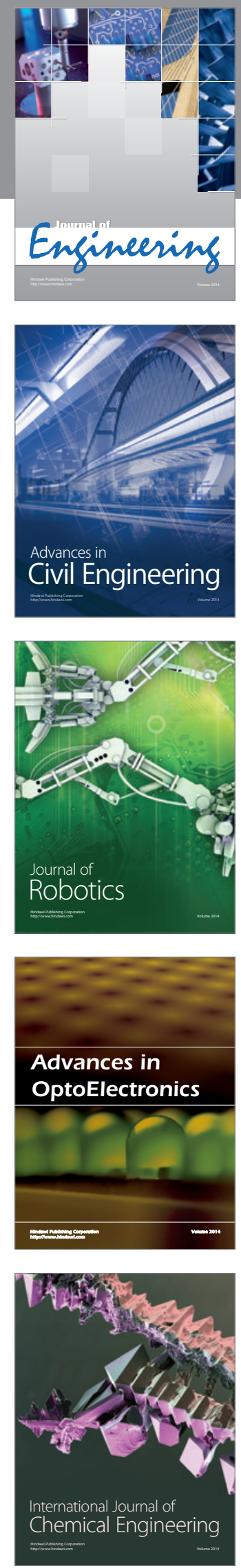

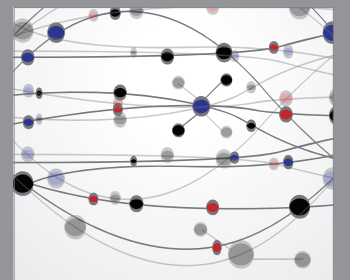

The Scientific World Journal
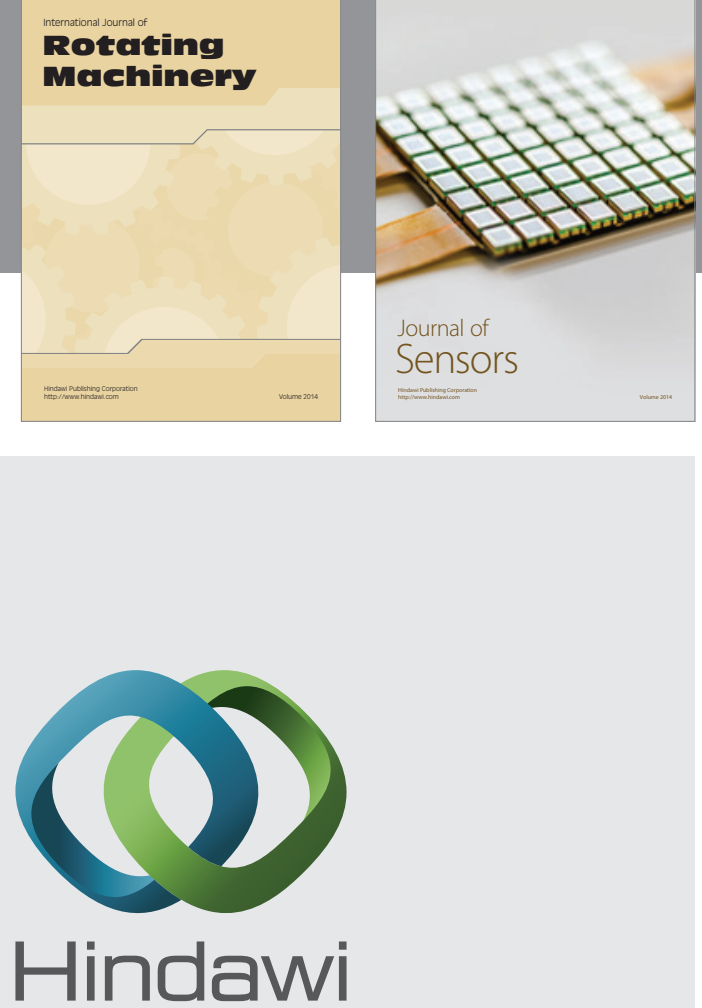

Submit your manuscripts at http://www.hindawi.com
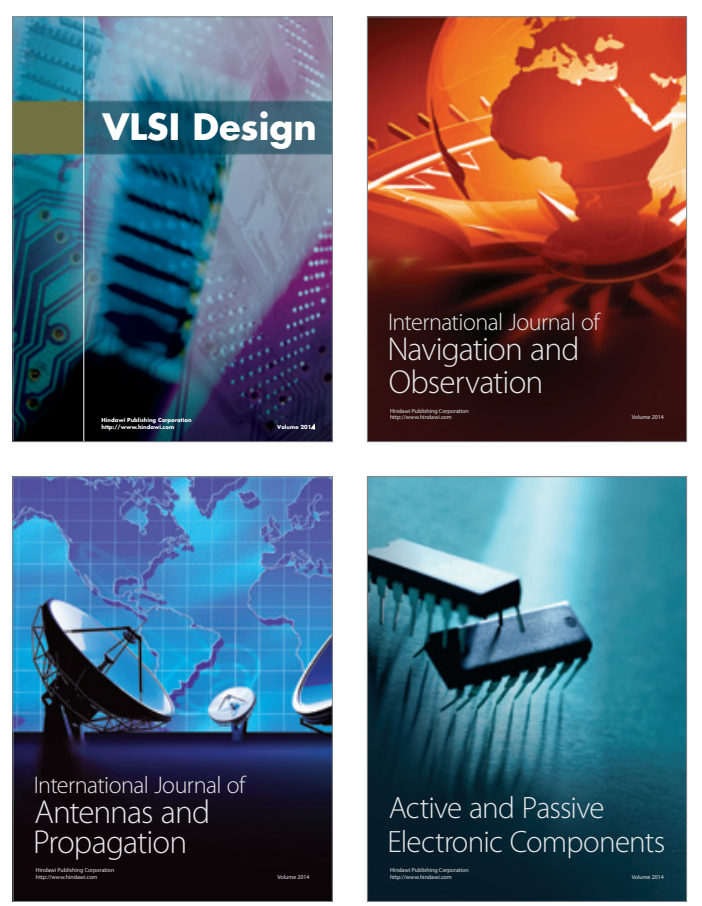
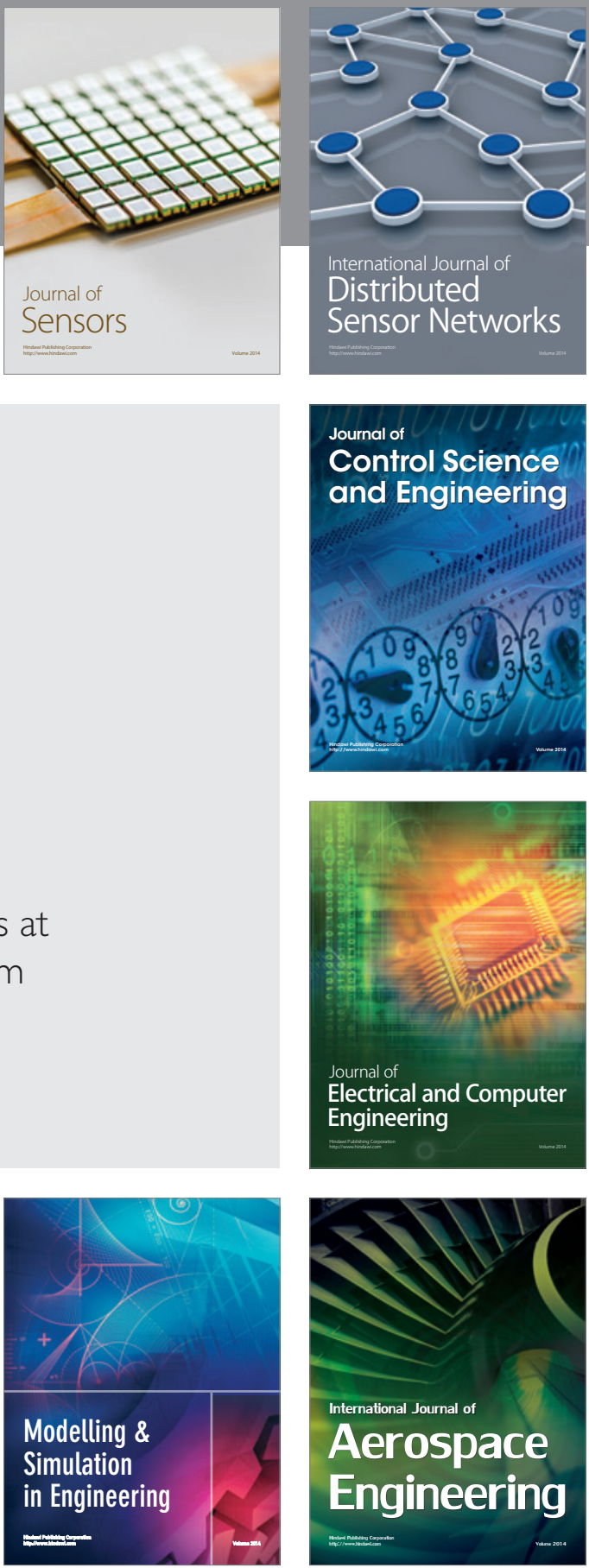

Journal of

Control Science

and Engineering
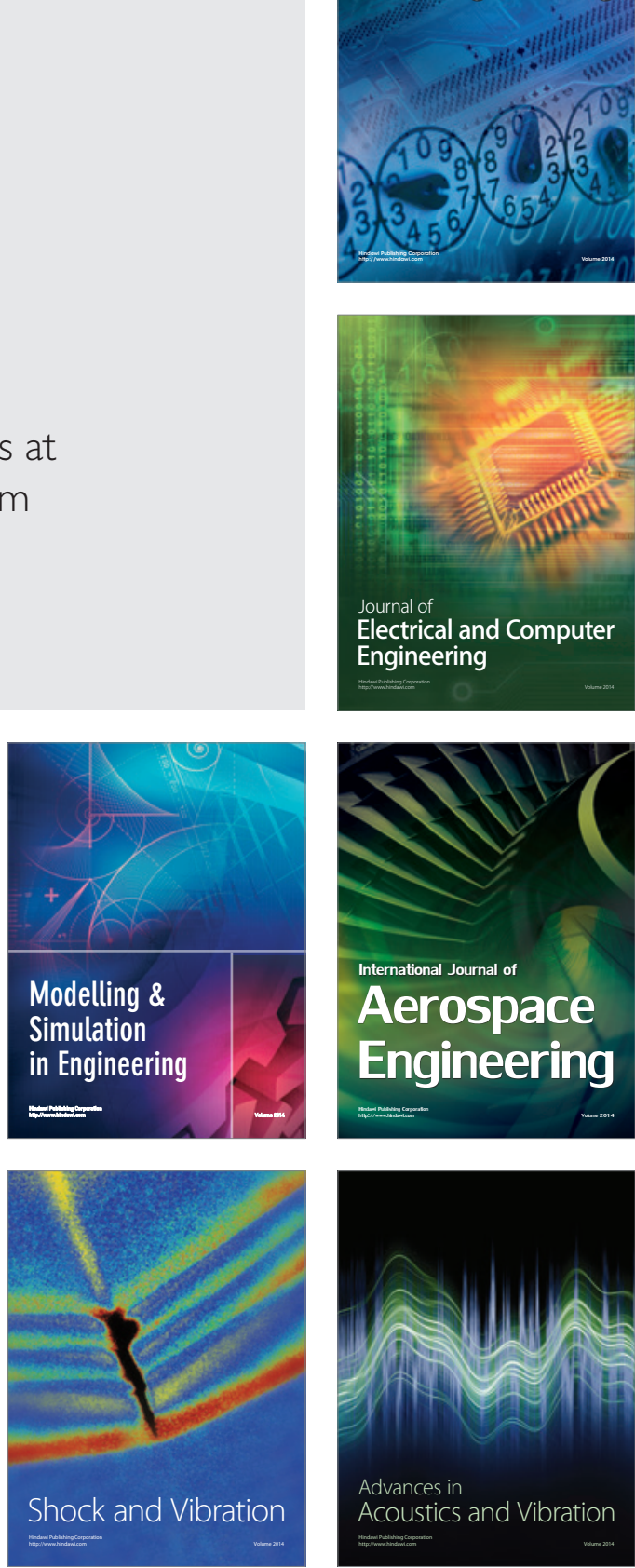